\author{
Jean-Michel Jeannin
}

\section{Einleitung}

Er gilt wegen seiner Früchte als einer der kuriosesten Bäume Afrikas: Kigelia africana (Abb. 1, 2), Leberwurstbaum, (fr. Saucisonnier, engl. Sausage Tree) [1]. Der Baum wird 15-30 m hoch und bildet eine dichte, weit ausladende Krone. Die Blätter sind unpaarig gefiedert und 20-60 cm lang. Die trompetenförmigen Blüten stehen in hängenden Rispen nach oben. Im Innern sind sie kastanienbraun, purpurrot oder purpurgelb, aussen orange oder grünlich-gelb, oft mit dunklen Flecken und gelben Streifen. Sie öffnen sich in der Dunkelheit und fallen am Morgen ab. Ihr Geruch gilt als unangenehm. Die Früchte gleichen einer grossen Leberwurst mit einer graugrünen, rauen Haut. Sie werden $30-$ $90 \mathrm{~cm}$ lang und bis $\mathrm{zu} 10 \mathrm{~kg}$ schwer. Sie hängen an seilartigen, 2-3 m langen verholzten Stielen. Das faserige Fruchtfleisch enthält zahlreiche Samen. Die unreife Frucht ist giftig, die reife Frucht ist essbar. Der Baum ist in Afrika heimisch und wird anderweitig in Gärten kultiviert.

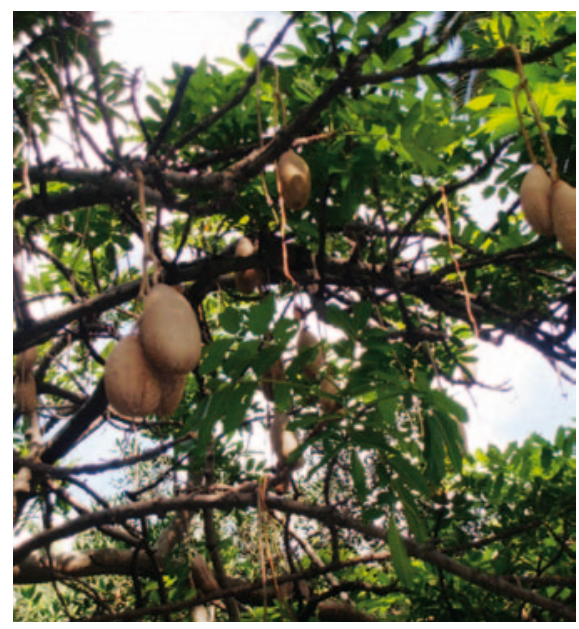

Abb. 1. K. africana, Ausschnitt aus der Krone (Madeira 2009).

\title{
Exotische Heilpflanzen (3)
}

\section{Kigelia africana (Lamarck) Bentham (Bignoniaceae)}

\section{Traditionelle Verwendung als Heilpflanze}

In Nordkamerun werden die Blüten zusammen mit Bohnen gekocht als Stärkungsmittel verabreicht. In Benin wird ein Stammrinden- oder WurzelDekokt gegen Dysenterie und ein Blätter-Dekokt gegen Gelbsucht eingesetzt. Im Gebiet von Nsukka wird ein Palmwein-Mazerat der Stammrinde zur Behandlung von Geschlechtskrankheiten eingenommen. In Ghana gilt die Frucht als Mittel gegen Dysenterie, Rheuma und Bandwürmer. Gegen Syphilis und Gonorrhöe wird die unreife Frucht oder eine Zubereitung der Rinde verwendet. In Tansania gilt die Frucht als Abortivum, die Stammrinde als Mittel gegen Epilepsie. In Nord-Zaire behandelt man Rheuma äusserlich mit dem Mazerat der Stammrinde oder innerlich mit dem Rindenpulver [1]. In Wasser gekochte Frucht- und Rindenstücke werden Kindern als Einlauf verabreicht, hauptsächlich gegen Würmer [2]. In vielen Ethnien wird der Saft der Frucht in Hautschnitte des Penis eingerieben,

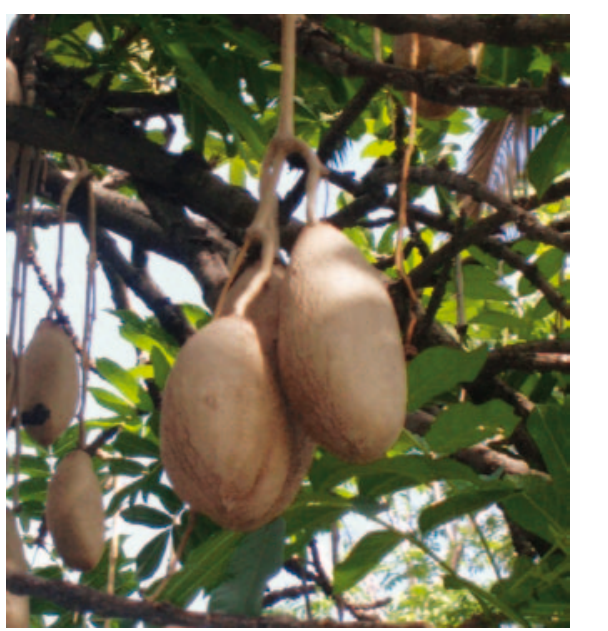

Abb. 2. K. africana, Früchte (Madeira 2009). damit er gross wird. In Senegal wird ein wässriges Dekokt der Früchte zur Vergrösserung auf die Brüste junger Frauen eingerieben [1]. Produkte mit dem Wirkstoff Kigelin werden bei uns zur Pflege und Vergrösserung der weiblichen Brust angeboten.

\section{Phytochemie, Pharmakologie}

Bereits bekannte Inhaltsstoffe: Catalpol, Ferulasäure, Kaffeesäure, Lapachol, Minecosid, Rhodamin B, Stigmasterol, $\beta$-Sitosterol, Vanillin, Verminosid. Neue, spezifische Stoffe: Kigelin, Kigelinol, Kigeliol, Demethylkigelin, Norviburtinal, Pinnatal, Isopinnatal [1]. In-vitro-Untersuchungen: Methylenchlorid-Extrakte der Stammrinde und der Frucht zeigten starke Zytotoxizität gegen Melanom- und gegen Nierenkarzinomzellen [3]. Ein methanolischer Extrakt der Rinde war stark wirksam gegen Salmonella typhi und Proteus vulgaris [4]. Die entzündungshemmende Wirkung eines ethanolischen Stammrinden-Extrakts war der von Aspirin und von Indomethacin ebenbürtig. Es war auch eine analgetische Wirkung nachweisbar [5].

\section{Literatur}

1 Neuwinger HD: Afrikanische Arzneipflanzen und Jagdgifte, ed 2. Stuttgart, WVG, 1998.

2 Saini S, et al.: Kigelia Africana (Lam.) Benth. An overview. Nat Prod Rad 2009;8:190-197.

- 3 Houghton PJ, et al.: Activity of extracts of Kigelia pinnata against melanoma and renal carcinoma cell lines. Planta Med 1994;60:430-433.

4 Jeyachandran R, Mahesh A: Antimicrobial evaluation of Kigelia africana (Lam). Res J Microbiol 2007;2:645-649.

5 Owolabi OJ, Omogbai EKI: Analgesic and antiinflammatory activities of the ethanolic stem bark extract of Kigelia africana (Bignoniaceae). Afr J Biotechnol 2007;6:582-585.

\section{KARGER}

Fax +497614520714 Information@Karger.de www.karger.com (c) 2010 S. Karger GmbH, Freiburg
Dipl. med. biol. Jean-Michel Jeannin Holeestrasse 43, 4054 Basel, Schweiz

Tel. +41 61-4215991, Fax -4230313

jmjeannin@dataworks.ch 